\title{
COMPORTAMENTO ORGANIZACIONAL: UM ESTUDO DE SATISFAÇÃO DE SECRETÁRIOS EXECUTIVOS NO ESTADO DO RS
}

\author{
ORGANIZATIONAL BEHAVIOR: A STUDY OF CASE ON THE LEVEL OF \\ SATISFACTION TO THE EXECUTIVE SECRETARY IN THE STATE OF RIO \\ GRANDE DO SUL
}

\author{
Tatiane Sartori \\ Graduada em Secretariado Executivo Bilíngue pela Universidade do Vale do Rio \\ dos Sinos - UNISINOS \\ tatianesartori@yahoo.com.br
}




\section{RESUMO}

O comportamento organizacional é um campo de estudos que investiga o impacto que indivíduos, grupos e a estrutura têm sobre o comportamento dentro das organizações, com o propósito de utilizar esse conhecimento para promover a melhoria da eficácia organizacional (CHIAVENATO,1999). O Secretário Executivo está inserido neste contexto, pois ao trabalhar com pessoas, não somente chefia, mas os demais colaboradores da organização, seu comportamento deve ser analisado para que ele possa melhorar e agregar valor ao seu trabalho diário, bem como nas decisões que deverá tomar. No caso deste estudo foi utilizada a pesquisa quantitativa que, segundo Roech (2005), é o tipo de pesquisa que o exame dos dados obtidos se utiliza de tratamento estatístico, busca garantir exatidão dos resultados, evitando distorções de análise e interpretações. As principais técnicas de coleta de dados são: entrevista, questionário, testes e observação. A coleta de dados foi feita por meio de questionários enviados a Secretários Executivos de empresas situadas em Porto Alegre (RS) e Região Metropolitana, e retornados via e-mail. A pesquisa também foi do tipo Survey, que para Roech (2005) se baseia em um interrogatório dos participantes, aos quais serão feitas várias perguntas que são de interesse do pesquisador. Este método tem como vantagem, em primeiro lugar, a aplicação, e em segundo, os dados obtidos são confiáveis, pois as respostas são limitadas às alternativas mencionadas e o uso das respostas fixas reduz a variabilidade nos resultados que pode ser causada pelas diferenças dos entrevistados.

Palavras-Chave: Comportamento Organizacional; Trabalho; Secretário Executivo. 


\section{ABSTRACT}

Organizational behavior is a field of study that investigates the impact that individuals, groups and structure have in the organizations in order to use this knowledge to promote the improvement of organizational effectiveness (CHIAVENATO, 1999). The Executive Secretary is in this context because when working with people not just leadership but the other employees of the organization its behavior should be analyzed so that it can improve and add value to their daily work, as well as, in the decisions that will have. In this study we used the quantitative research that to Roech (2005), is the kind of research examining the data obtained is used for statistical analysis, seeks to ensure accuracy of the results, avoiding distortions of analysis and interpretations. The techniques of data collection are: interviews, questionnaires, tests and observation. Data collection was done through questionnaires sent to the Executive Secretaries of companies located in Porto Alegre (RS) and the Metropolitan Area, and returned by email. The research was also the type Survey that to Roech (2005) is based on an interrogation of the participants which will be made to several questions that are of interest to the researcher. This method has the advantage, firstly, the application, and second, the data obtained are reliable because the answers are limited to the alternatives mentioned and the use of fixed response reduces the variability in results that can be caused by differences interviewed.

Keywords: Organizational Behavior; Work; Executive Secretary. 


\section{INTRODUÇÃO}

A profissão de Secretário Executivo está crescendo e tomando dimensões importantes no mercado de trabalho e dentro das organizações. O desenvolvimento profissional do secretário remodelou-se diante das novas situações e exigências do mercado revelando uma nova forma de assessoria executiva, sendo esta mais ampla e competente.

O profissional de secretariado tem atribuições que envolvem não só o seu conhecimento específico, mas também o conhecimento de um todo da organização onde está inserido. Entender o comportamento deste profissional no seu ambiente de trabalho, através de ferramentas que indiquem seu grau de satisfação ou insatisfação, vai auxiliá-lo a melhorar e reivindicar melhorias dentro da organização. $O$ estudo do comportamento organizacional faz-se importante também para entender como a organização trabalha a motivação e o desenvolvimento deste profissional, ou seja, quais são as práticas adotadas para que o colaborador e a organização trabalhem com os mesmos objetivos. Por isso, estudar o comportamento organizacional torna-se um ponto importante, pois é uma forma de entender como as organizações e colaboradores se comportam, e com isso entender os processos e dificuldades do profissional. É necessário avaliar se os funcionários estão motivados para o trabalho e se as empresas estão conseguindo preencher as expectativas de seus colaboradores.

Chiavenato (1999) define que o Comportamento Organizacional é o estudo da dinâmica das organizações e como os grupos e pessoas se comportam dentro delas. É uma ciência interdisciplinar. Como a organização é um sistema cooperativo racional, ela somente pode alcançar objetivos se as pessoas que a compõe coordenarem seus esforços a fim de alcançar algo que individualmente jamais conseguiriam.

De acordo com Maximiliano (2000), o objetivo implícito do enfoque comportamental é fornecer instrumentos para a administração das organizações, tendo por base o conhecimento sobre o comportamento das pessoas, como indivíduos e membros de grupos.

O estudo do Comportamento Humano no trabalho torna-se importante para entender melhor o contexto de clima dentro da organização e perante 0

Revista de Gestão e Secretariado, São Paulo, v. 2, n. 1, p.32-55, jan./jun. 2011. 
funcionário. Vive-se hoje em uma era marcada por inúmeros contrastes. Se, por um lado, a tecnologia e a rápida comunicação proporcionam à população uma sensível melhoria, por outro lado estas transformações influenciaram uma nova realidade mundial, gerando altas taxas de desemprego e diminuição do emprego formal.

Para Xavier (1973), nos dias atuais tem havido a preocupação constante do profissional em tornar-se empregável, o que sugere constantes mudanças nos paradigmas atitudinais e comportamentais, visando à excelência empresarial e pessoal do colaborador.

Neste contexto, o presente trabalho pretende analisar como o Comportamento Organizacional se insere no dia a dia do trabalhador, e em específico, no bem-estar do Secretário Executivo. Pretende, também, descrever a importância do trabalho e do reconhecimento do profissional pela organização. O objetivo é identificar e analisar se o Secretário Executivo se sente inserido na organização e de que forma isso acontece.

O estudo é do tipo quantitativo e de caráter descritivo. A pesquisa bibliográfica é utilizada para construir a base de análise proposta. Gil (2009) descreve este tipo de pesquisa como sendo desenvolvida a partir de materiais já elaborados, constituído basicamente de livros e artigos científicos. Para obter os resultados desejados a coleta de dados foi realizada por meio de um questionário. Por fim, houve a avaliação dos dados e apresentados os resultados e conclusões.

\section{REFERENCIAL TEÓRICO}

\subsection{COMPORTAMENTO HUMANO NAS ORGANIZAÇÕES}

O estudo do comportamento humano nos remete a entender como o ser humano reage a determinadas situações seja na prática do dia a dia, seja em momentos de pressão ou em determinadas situações que exijam personalidade individual de cada indivíduo. Conforme Xavier (1973), a ciência do 
Comportamento Organizacional preocupa-se com a relação entre o homem e seu trabalho.

Knaane (1999) define comportamento como o conjunto de reações de um sistema dinâmico em meio às interações propiciadas pelo meio onde está inserido. Alguns exemplos de comportamentos citados por ele são: comportamento social, comportamento humano, comportamento animal, comportamento atmosférico, etc.

Para Nuttin (1983), o termo comportamento é corretamente empregado em sentidos variados. Na psicologia, há interesse em reservar o termo para a categoria de atividades dirigidas, pelas quais um organismo, enquanto centro de elaboração e de utilização de informação, age sobre as relações que o unem ao meio.

A partir dos anos 1980, o mercado vem reconhecendo a importância de as empresas definirem uma cultura organizacional. Os comportamentos e atitudes que garantem a integração das pessoas dentro da empresa são essenciais para estabelecer a sua identidade, o que tem um impacto direto, negativo ou positivo, sobre a motivação e, consequentemente, sobre a produtividade dos colaboradores. (KNAANE, 1999)

Davis \& Newstrom (1989) explicam comportamento organizacional como um estudo e aplicação do conhecimento sobre como as pessoas agem dentro das organizações. Os elementos chave do Comportamento Organizacional são: pessoas, estrutura, tecnologia e ambiente no qual a organização opera.

Para administrar uma empresa atualmente, é necessário muito mais do que planejar, organizar e controlar. É necessário um alto nível de administração para lidar com os clientes, fornecedores e colaboradores.

Assim como as pessoas têm necessidades psicológicas, têm também papéis sociais e status. O comportamento das pessoas é influenciado pelo grupo onde cada um atua da mesma forma que pelos impulsos individuais. Essa relação é muito importante, pois se pode identificar o que o trabalhador espera da empresa onde atua e também o que a empresa faz para que o trabalhador tenha um bom desempenho em seu trabalho. (DAVIS \& NEWSTROM, 1989)

Quando se trabalha com pessoas, é importante ressaltar o valor de cada indivíduo dentro da organização, pois ninguém tem os mesmos pensamentos, ou

Revista de Gestão e Secretariado, São Paulo, v. 2, n. 1, p.32-55, jan./jun. 2011. 
reage da mesma forma às situações. Cada indivíduo tem o seu papel seja na sociedade, na família ou na empresa. Isso se faz importante para que a individualidade seja mantida, pois transformará o ambiente organizacional em um lugar onde terá a diversidade de ideias e crescimento do todo, grupo e organização. (DAVIS \& NEWSTROM, 1989)

Para os gestores, a importância do estudo do comportamento organizacional auxilia num maior entendimento da organização e dos problemas que ocorrem no dia a dia. Faz com que eles tenham uma visão maior de todo o organizacional, e os auxilie na tomada de decisão quanto aos processos mais complexos, nas situações mais difíceis, as quais podem surgir em qualquer momento do trabalho. (KNAANE, 1999)

O problema de deterioração cultural de uma empresa é a consequência direta da pouca atenção que a alta gerência dedica a esse fator. Hipnotizados por lucros e resultados, muitos executivos deixam de considerar que os números vêm depois dos comportamentos e esquecem de que lidar com o fator humano pode fazer toda a diferença nessas horas. (KNAANE, 1999)

Dentro das organizações, um dos focos principais é o empregado, pois é a partir dele que os processos começam a funcionar. As pessoas representam o sistema social interno da organização. Elas se constituem de indivíduos e grupos, sejam grandes ou pequenos. A organização muda diariamente em função das mudanças e da globalização. As pessoas são seres que estão vivendo, pensando e sentindo que trabalham na organização para atingirem seus objetivos. (KNAANE, 1999)

Para Nuttin (1983), o comportamento é um fenômeno global e integrado onde todos os processos colaboram para o que se chama de "fazer alguma coisa em determinada situação". O indivíduo faz alguma coisa, o que ele faz se refere a uma situação na qual ele se encontra. A ciência comportamental não é somente o estudo de uma série de processos numa série justaposta de capítulos sobre percepção, memória e motivação. Ela é a investigação do papel desempenhado por cada um desses processos, seja na construção do mundo comportamental, no processamento da dinâmica do comportamento, ou na ação sobre uma situação.

Revista de Gestão e Secretariado, São Paulo, v. 2, n. 1, p.32-55, jan./jun. 2011. 
Neste novo contexto de globalização, as organizações estão tendo de se ajustar em servir as pessoas, em lugar de as pessoas existirem para servir as organizações. Com isso está sendo necessário um novo ajuste no relacionamento organizacional, pois as empresas operam pelas mãos dos colaboradores que dela fazem parte e eles têm, cada vez mais, buscando a tomada de decisões e o seu lugar diante do mercado de trabalho. Isso incentiva o trabalhador e também a organização, pois os dois buscam novas formas de crescimento.

\subsection{CONCEPÇÕES SOBRE O TRABALHO}

Nos dias atuais, tem havido a preocupação constante do profissional em tornar-se empregável o que sugere constantes mudanças nos paradigmas atitudinais e comportamentais, visando à excelência empresarial e pessoal do colaborador. (XAVIER, 1973)

Vivemos em uma era marcada por inúmeros contrastes. Por um lado a crescente globalização, integrando vários países com facilidades tecnológicas e avanços cada vez mais rápidos e fáceis, por outro, a falta de mão de obra especializada no Brasil, para trabalhos de operações simples, como o ramo da construção civil, torneiro de obras e operadores de máquinas. Estes são só exemplos divulgados pela mídia, mas que servem de parâmetro para uma avaliação quanto às aptidões no trabalho.

Para Xavier (1973), na era das novas tecnologias de comunicação e informação, há um aumento das exigências quanto às aptidões do trabalho, onde a busca é por pessoas com conhecimentos mais amplos e com capacidade para a resolução de problemas. $O$ trabalhador deve desenvolver diferentes competências e multifunções.

A mesma pessoa que há alguns anos operava uma máquina na fábrica ou apertava parafusos, está sendo substituída por máquinas mais modernas, as quais estão ocupando o espaço do profissional. Essa nova tecnologia faz com que profissionais busquem uma adequação para o mercado, fazendo cursos, aprendendo a lidar com novas máquinas e sistemas. Em algumas empresas a tecnologia é o ponto forte na fabricação do produto. O que deve ser lembrado é que para operar a máquina é necessário o conhecimento humano.

Revista de Gestão e Secretariado, São Paulo, v. 2, n. 1, p.32-55, jan./jun. 2011. 
Segundo Robbins (2004), muitas atividades realizadas pelo trabalhador obedecem a uma série de regras e passos preestabelecidos, em que ele, por vezes, não sabe o que está fazendo e por que o faz. Tais situações impossibilitam-no de raciocinar e visam tão somente à otimização do sistema. A limitada participação nos processos produtivos tem ocasionado o descompromisso do trabalhador, gerando impedimentos que atuam tanto em termos individuais como grupais. Os problemas daí advindos estendem-se ao contexto em que o trabalho é realizado, ocasionando problemas em sua organização e no nível de satisfação dos funcionários, principalmente quanto à necessidade de integração de reconhecimento.

O trabalho é essencial para o crescimento do ser humano. Ele possibilita a busca de resultados pessoais e faz com que haja uma realização profissional, a qual auxilia na realização dos planos e desejos do indivíduo. $O$ trabalho potencializa a criatividade e auxilia na sua melhoria, aprimorando a integração entre empresa e empregado. A intensidade dessa relação varia de acordo com o grau de influência das partes sobre o sistema de valores do ser humano com sua autoestima. Essas relações estão vinculadas com as expectativas e vivências dos envolvidos e com as oportunidades e disponibilidades que o próprio meio social oferece a cada um. O desenvolvimento do trabalho está interligado à satisfação do trabalhador, pois quanto maior sua satisfação, melhor o seu desempenho dentro da organização potencializando sua criatividade e motivação. (KNAANE, 1999)

Segundo Robbins (2004), do ponto de vista psicológico, o trabalho provoca diferentes graus de motivação e de satisfação no trabalhador, principalmente quanto à forma e ao meio no qual desempenha sua tarefa. As diversas abordagens sobre a motivação humana destacam o conceito de necessidade e o conceito de expectativa. Não basta considerar as necessidades como determinantes do comportamento do trabalhador, é preciso considerar também em que grau o mesmo percebe as condições existentes no ambiente organizacional, como facilitadoras ou não, para o alcance de seus objetivos e de suas necessidades.

Para Robbins (2004), o trabalhador pode estar satisfeito parcial ou até plenamente, sem que com isso tenha atingido o nível de realização pessoal ou

Revista de Gestão e Secretariado, São Paulo, v. 2, n. 1, p.32-55, jan./jun. 2011. 
profissional em dado contexto organizacional; contrariamente, pode ocorrer que a ação de enfrentar obstáculos organizacionais possa trazer-lhe satisfação e realização, à medida que ela esteja associada às expectativas e possibilidades percebidas pelos indivíduos. Tem-se que o trabalho assume distintas finalidades.

\subsection{SATISFAÇÃO NO TRABALHO}

Satisfação no trabalho é um conjunto de sentimentos favoráveis ou desfavoráveis com os quais os empregados veem seu trabalho. Há uma diferença importante entre estes sentimentos associados ao cargo e dois outros elementos das atitudes dos empregados. É o sentimento de relativo prazer ou dor que difere de raciocínios objetivos e intenções comportamentais. (DAVIS \& NEWSTROM, 1989). A satisfação no trabalho é um estado de prazer emocional resultante da avaliação que um profissional faz sobre até que ponto o seu trabalho apresenta a capacidade de facilitar ou permitir o atendimento de seus objetivos e valores. (LOCKE apud BERGAMINE \& CODA, 1990)

Davis \& Newstrom (1989) citam que a satisfação no trabalho pode ser encarada com uma atitude global ou então ser aplicada a determinadas partes do cargo ocupado pelo indivíduo. Satisfação no trabalho, como qualquer outro tipo de atitude, é geralmente formada durante um determinado período de tempo, na medida em que o empregado vai obtendo informações sobre o ambiente de trabalho. Todavia, a satisfação no trabalho é dinâmica, uma vez que pode deteriorar-se muito mais rapidamente do que o tempo necessário para desenvolver-se. Representa uma parcela da satisfação com a vida. A natureza do ambiente de alguém fora do trabalho influencia seus sentimentos no trabalho. Dado que um cargo é uma parte importante da vida da pessoa, a satisfação no trabalho influencia também o sentimento de satisfação global com a vida de uma pessoa.

Cada vez mais as empresas estão interessadas em reter seus talentos, buscando além de vantagens financeiras, outros atrativos como forma de melhorar a produtividade e a satisfação de seus colaboradores. Com maiores incentivos, o profissional sente-se mais seguro ao realizar seu trabalho e fica mais satisfeito com a organização como um todo.

Revista de Gestão e Secretariado, São Paulo, v. 2, n. 1, p.32-55, jan./jun. 2011. 
Segundo Knaane (1999) é importante manter um clima favorável, no qual as pessoas possam desenvolver seu potencial e alcançar a realização no trabalho. O autor cita ainda que a qualidade de vida está diretamente relacionada com as necessidades e expectativas do ser humano e com a obtenção da satisfação dessas necessidades. Tem relação com o bem-estar do indivíduo em seu ambiente de trabalho, sua forma de expressar relações saudáveis e harmônicas dentro da organização. Deve-se lembrar de que cada organização possui sua cultura organizacional, a qual se constitui a partir de valores que vão sendo cultuados pelos membros da organização ao longo do tempo.

Muitas pessoas descobrem que existe uma grande diferença entre aquilo que esperam de seu trabalho e aquilo que realmente dele obtém. Ao entrar na empresa, a euforia pela obtenção de resultados e novos desafios faz com que a motivação seja elevada e a sensação de bem-estar aumente. Isso se deve ao "novo", às novas formas que o ser humano vai descobrir neste novo momento de sua vida. A partir do momento em que o funcionário não obtém o que era esperado de sua parte para com a organização, surge a frustração, a qual abaixa o nível da motivação e faz seu rendimento cair. (DAVIS \& NEWSTROM, 1989)

Daí surge a necessidade da comunicação, da informação, por parte da empresa e de suas reais expectativas para com o funcionário. A importância desses fatores varia de pessoa para pessoa o que determina a personalidade, os interesses, os conhecimentos e treinamentos. Neste processo, a empresa deve tentar entender quais são as expectativas dos funcionários e o que eles esperam da organização como membros participativos que são. (DAVIS \& NEWSTROM, 1989)

A satisfação do ser humano no trabalho é uma conquista diária. Vários fatores interferem na satisfação e no desenvolvimento do funcionário, como por exemplo, o relacionamento interno entre os funcionários, o relacionamento e o reconhecimento perante a chefia, a importância da qualidade de vida do indivíduo dentro do ambiente de trabalho, entre outros. A organização faz parte da vida do indivíduo e ele busca, através dela, sua satisfação e atingimento das metas pessoais, não esquecendo que sua vida pessoal também é importante e a relação indivíduo-empresa andam juntas. (WAGNER \& HOLLENBECK, 1999)

Revista de Gestão e Secretariado, São Paulo, v. 2, n. 1, p.32-55, jan./jun. 2011. 
A organização deve fazer sua parte para que a qualidade de vida do funcionário e para que sua satisfação no trabalho seja suprida. As organizações exercem grande influência sobre os estados mentais e emocionais dos indivíduos que as compõem. Elas podem atuar como ambiente integrador e enriquecedor para as pessoas que nelas trabalham, ou podem desagregar e manipular as pessoas, que tendem a ser absorvidas por elas. Podem influenciar no clima organizacional, gerando manifestações comportamentais inadequadas e inaptas, quer do ponto de vista individual, quer do ponto de vista grupal. (WAGNER \& HOLLENBECK, 1999)

Empregados mais satisfeitos estão menos propensos a pensar em pedir demissão, procurar um novo trabalho ou mesmo anunciar a intenção de deixar a empresa, apresentando maior probabilidade de ficarem mais tempo com o atual empregador. Uma atmosfera de frustração numa empresa pode ser facilmente identificada pela presença de sinais como: excessiva crítica à administração, comentários maliciosos, expressões de queixas superficiais, atrasos e outros comportamentos negativos que começam a fazer parte do dia a dia do indivíduo. Um ambiente de trabalho desfavorável, onde há intriga, fofocas, falta de relacionamento e conversas, além de outros fatores, faz com que os trabalhadores tenham comportamentos errôneos, estresse, inadequações ao trabalho e ao meio ao qual estão inseridos. (WAGNER \& HOLLENGECK, 1999)

Pessoas insatisfeitas são mais ansiosas, menos comunicativas, menos amistosas, emocionalmente propensas ao desequilíbrio, mostram aborrecimento e distração. É muito comum achar baixo nível na satisfação entre trabalhadores de baixo nível social, principalmente quando os laços familiares são relativamente fracos, as moradias são precárias e quando são limitadas as oportunidades de se adquirir estáveis hábitos de trabalho, como estabilidade de horário, responsabilidade e ambição. (KNAANE, 1999)

O ambiente de trabalho é um lugar onde o indivíduo passa a maior parte do seu tempo durante o dia. Mas, muitas vezes, o ambiente não é visto em igualdade por todos. Pode-se perceber satisfação no local de trabalho por parte de alguns funcionários e repúdio por parte de outros. Isso se dá pela diferença de personalidade de cada indivíduo, pois a adequação também depende da forma como o indivíduo vê seu ambiente de trabalho e o que ele visualiza para si

Revista de Gestão e Secretariado, São Paulo, v. 2, n. 1, p.32-55, jan./jun. 2011. 
mesmo como funcionário. Por isso faz-se importante que a organização tenha um feedback do funcionário e volte seus interesses a essas respostas assim fará com que todos possam se adequar e ter resultados mais positivos. Oferecer condições para que o trabalhador desenvolva todo o seu potencial de forma produtiva e feliz é um ponto muito positivo para uma administração bem sucedida. (XAVIER, 1973)

Conforme Davis \& Newstrom (1989), quanto maior o envolvimento no trabalho, mais dedicados e produtivos serão os trabalhadores. Desempenhos elevados e consequentes recompensas promovem a satisfação, através da junção desempenho-satisfação-esforço. Níveis maiores de satisfação estão frequentemente ligados a taxas mais baixas de rotatividade de pessoal e de ausência no trabalho. Empregados mais comprometidos apresentam maior probabilidade de assumirem os valores e crenças da organização.

Alguns autores mostram que a falta de oportunidade para crescimento pode ser forte justificativa para uma pessoa não gostar de seu trabalho. Há inúmeras razões pelas quais as pessoas gostam do seu trabalho. Um empregado pode gostar do seu, por ter habilidade e treinamento para isso. Outro pode gostar pelo reconhecimento que advém do trabalho. De qualquer maneira há fatores importantes em cada trabalho que contribuem de forma positiva e negativa para a satisfação do empregado.

\section{METODOLOGIA}

No caso deste estudo foi utilizada a pesquisa quantitativa que, segundo Roech (2005), é o tipo de pesquisa em que no exame dos dados obtidos utilizase o tratamento estatístico, busca garantir exatidão dos resultados, evitando distorções de análise e interpretações. As principais técnicas de coleta de dados são: entrevista, questionário, testes e observação. No caso do estudo, a coleta de dados foi feita por meio de questionários enviados e retornados via e-mail.

A pesquisa também foi do tipo Survey, que, para Roech (2005), se baseia em um interrogatório dos participantes, aos quais serão feitas várias perguntas que são de interesse do pesquisador. Este método tem como vantagem, em

Revista de Gestão e Secretariado, São Paulo, v. 2, n. 1, p.32-55, jan./jun. 2011. 
primeiro lugar, a aplicação, e em segundo, os dados obtidos são confiáveis, pois as respostas são limitadas às alternativas mencionadas e o uso das respostas fixas reduz a variabilidade nos resultados que pode ser causada pelas diferenças dos entrevistados.

O questionário foi enviado a 45 Secretários Executivos, todos do sexo feminino, com média de idade entre 25 e 40 anos, formados ou com curso em andamento em Secretariado Executivo, que trabalham em empresas situadas no Rio Grande do Sul, mais precisamente em Porto Alegre e Região Metropolitana. Destes 45 questionários enviados, somente 25 deles foram devolvidos, os quais serviram de material para o desenvolvimento dos resultados.

O questionário foi composto com respostas fechadas por escala de Likert com cinco níveis, que vão de "concordo totalmente" até "discordo totalmente". Também foi utilizada a forma de escala para questões de nível 5 que vão da primeira mais importante até a quinta mais importante. Para Roesch (2005) há uma ampla utilização da escala de Likert, que atribui pontos a diferentes categorias de resposta, criando assim uma escala artificial de pontos que variam de 1 a 5 . E o principal propósito de se transformar uma escala ordinal em uma linear é poder utilizar estatísticas paramétricas, para poder ser realizada uma análise mais detalhada dos dados.

\section{ANÁlise dos RESULTADOS}

A análise dos resultados baseia-se nas respostas enviadas pelos profissionais, conforme descrito acima, e buscou saber questões referentes ao comportamento organizacional, motivação e satisfação no trabalho.

Buscando identificar qual o grau de importância dos fatores motivacionais para os secretários, puderam-se formular as questões quanto ao nível de concordância diante da integração entre os setores da organização e o relacionamento interpessoal. Assim foi possível a verificação de como está o relacionamento do profissional secretário com seu grupo de trabalho e como a empresa tem atuado diante da integração com seus funcionários.

Revista de Gestão e Secretariado, São Paulo, v. 2, n. 1, p.32-55, jan./jun. 2011. 
O gráfico 1 demonstra o grau de satisfação dos secretários quanto ao sentir-se à vontade para solicitar ou oferecer ajuda aos colegas de trabalho.

Gráfico 1 - Facilidade em solicitar ou oferecer ajuda aos colegas de trabalho.

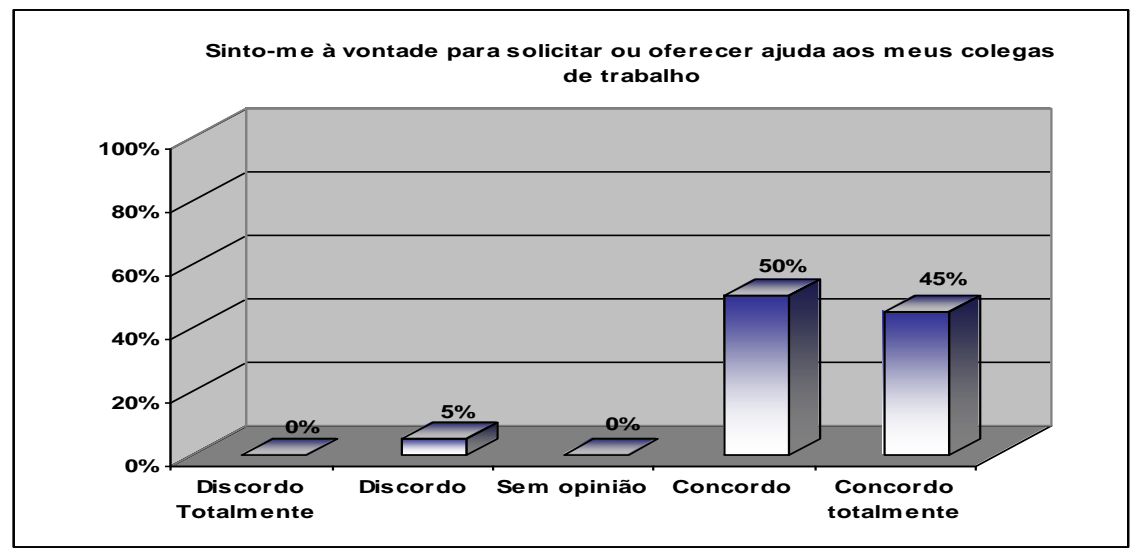

Fonte: Elaborado pelo autor com base em dados coletados.

Conforme demonstrado no gráfico, $45 \%$ dos entrevistados concordaram totalmente e $50 \%$ concordaram dizendo sentir-se a vontade para solicitar e oferecer ajuda, sendo que somente $5 \%$ discordaram. O número de concordância demonstra que há facilidade quanto ao relacionamento com os colegas de trabalho, sendo este um fator importante no dia a dia do secretário, pois ele trabalha diretamente com pessoas, sejam elas colaboradores, gerentes ou diretores. Desta forma ele obtém dados e informações, aumentando assim o seu conhecimento seja da organização ou dos processos do seu trabalho. Isso se torna importante não só para o seu crescimento profissional como também pela possibilidade de auxiliar a todos os que estão em seu grupo de trabalho, demonstrando ser uma facilitadora de informações.

Considerando a importância do trabalho em grupo para o bom andamento dos processos e alcance das metas, o gráfico 2 demonstra qual o grau de cooperação do grupo para que os resultados sejam atendidos.

Gráfico 2 - No meu setor existe a cooperação de todos para que os resultados sejam atingidos. 


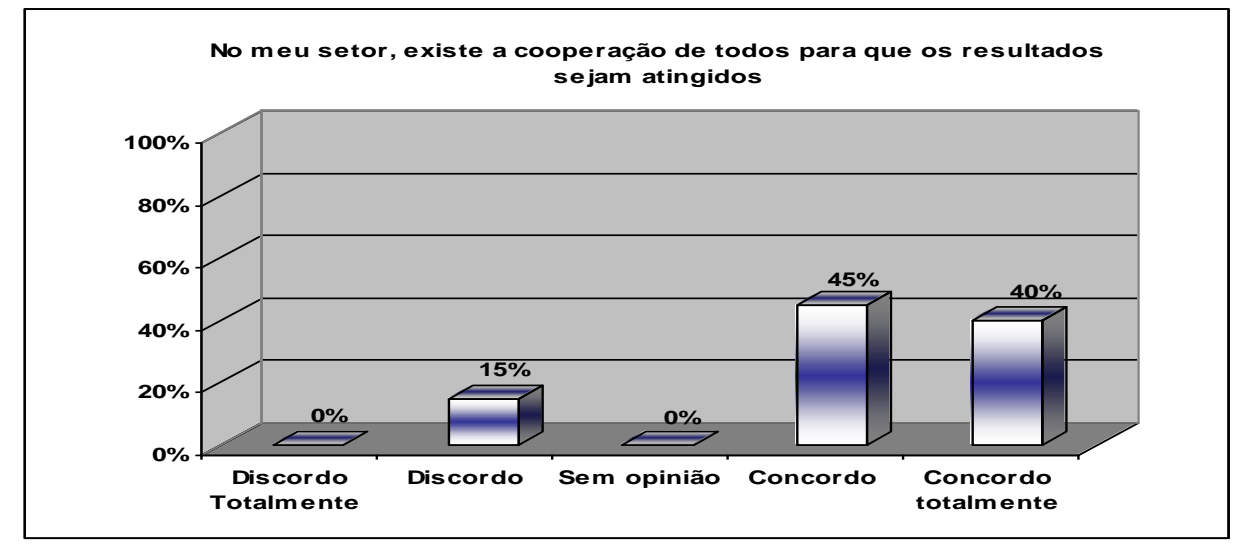

Fonte: Elaborado pelo autor com base em dados coletados.

Para que haja um trabalho produtivo, no processo de interação e interdependência que se estabelece no ambiente de trabalho, o nível de relacionamento precisa estar embasado em cooperação, confiança mútua e lealdade (RIBEIRO, 1988). O gráfico mostra que 40\% dos entrevistados concordaram totalmente que há cooperação em grupo no ambiente de trabalho, $45 \%$ concordaram e $15 \%$ discordaram. Neste caso, não houve discordância total e nem falta de opinião. Verifica-se, considerando os resultados da pesquisa, que a cooperação em grupo é um fator importante para a obtenção dos resultados da organização. Não se consegue trabalhar sozinho, e para isso é importante que o relacionamento interpessoal seja favorável no ambiente de trabalho. Tendo o secretário o papel de facilitador das tarefas, é importante que ele também tenha o comprometimento para o alcance das metas, fazendo com que os resultados sejam positivos e obtenha o apoio dos demais para exercer suas funções.

Ao procurar perceber se o bem-estar do funcionário é importante para a organização, foi perguntado aos entrevistados se a empresa onde trabalham se preocupa com o bem-estar de todos os colaboradores e $50 \%$ deles responderam que sim, porém 30\% responderam que discordam.

Gráfico 3 - Preocupação da empresa com o bem-estar dos funcionários.

Revista de Gestão e Secretariado, São Paulo, v. 2, n. 1, p.32-55, jan./jun. 2011. 


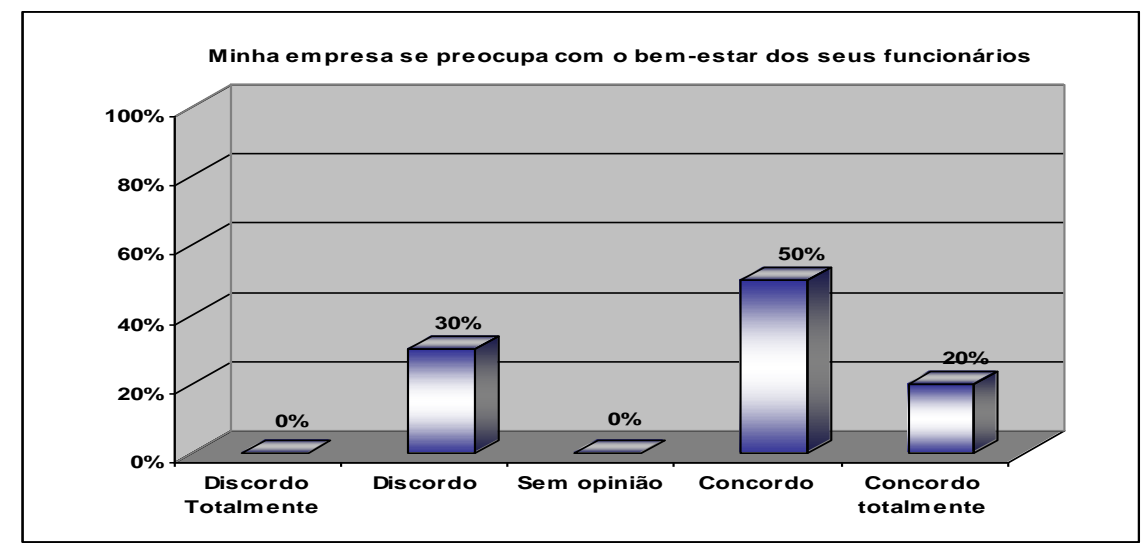

Fonte: Elaborado pelo autor com base em dados coletados.

Verifica-se que o número de entrevistados que discordaram está bastante elevado. Conforme citado por Knaane (1999), a qualidade de vida e o bem-estar do funcionário referem-se à satisfação das necessidades do indivíduo, afetando as atitudes pessoais e comportamentais, a criatividade, a vontade de inovar ou aceitar mudanças, a capacidade de adaptar-se no ambiente de trabalho e o grau de motivação interna para o trabalho. O bem-estar do funcionário é importante, pois implica facilitar ou dificultar a obtenção daquilo que ele busca dentro da organização, influenciando assim, nos resultados do seu trabalho.

É importante que as organizações revejam seus conceitos quanto ao bemestar e busquem melhorias em seu ambiente de trabalho para uma melhor valorização do profissional que nela atua. Um indivíduo que está satisfeito com o seu trabalho, que se sente valorizado, torna-se mais produtivo e consegue agregar valor em seu trabalho diário; por isso torna-se importante cuidar do seu bem-estar por meio de incentivos, melhoria de processos de qualidade, produtividade, entre outras ações que podem ser tomadas pelas organizações neste sentido.

A pesquisa abordou também a importância do trabalho para o Secretário Executivo. Na avaliação em relação ao trabalho, buscou-se saber como estava o relacionamento do funcionário com o seu trabalho, reconhecendo o que motiva ou desmotiva o profissional e se as empresas têm mostrado o reconhecimento diante do trabalho realizado pelo secretário.

A pesquisa demonstrou satisfação quanto ao gosto pelo trabalho, pois $65 \%$ concordaram totalmente, não havendo discordância. Há inúmeras razões 
pelas quais as pessoas gostam do seu trabalho. Um empregado pode gostar do seu por ter habilidade e treinamento para isso. Outro pode gostar pelo reconhecimento que advém do trabalho. De qualquer maneira há fatores importantes em cada trabalho que contribuem de forma positiva e negativa para a satisfação do empregado. (XAVIER, 1973)

Para os secretários entrevistados, o trabalho exercido é de extrema identificação, pois a maioria gosta do que faz. Observa-se, através dos dados, que a principal forma de melhorar cada vez mais seu trabalho é trabalhar com o que gosta, pois assim a autoestima aumenta e a motivação permanece mesmo em tarefas rotineiras (as quais todos os secretários têm no seu dia a dia, como por exemplo, controle de agenda, correspondência, atendimento telefônico, etc).

Ainda relacionado ao trabalho, os entrevistados foram questionados quanto à liberdade na tomada de decisões. O gráfico 4 demonstra o resultado.

Gráfico 4 - Liberdade na tomada de decisões.

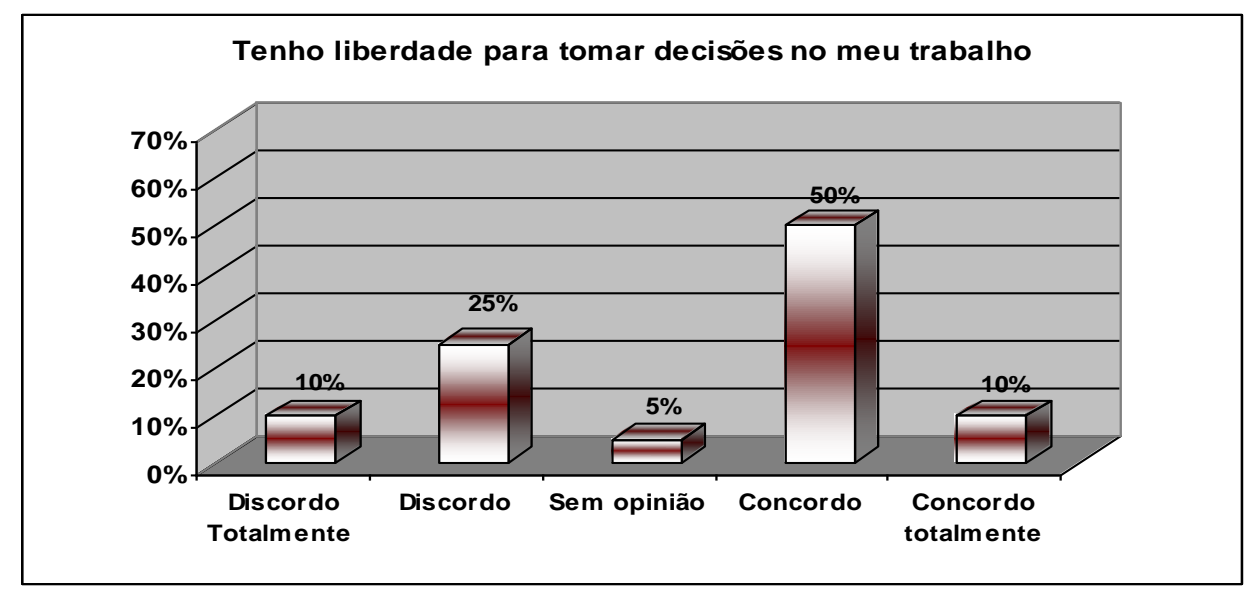

Fonte: Elaborado pelo autor com base em dados coletados.

Observa-se, através do gráfico, que o número de discordância está próximo da metade do número de concordância, sendo que, atualmente, o secretário busca ter um maior poder de decisão dentro da empresas. Não se

Revista de Gestão e Secretariado, São Paulo, v. 2, n. 1, p.32-55, jan./jun. 2011. 
sabe, através destes dados, o porquê de os profissionais não terem um grau maior de tomada de decisão, mas pôde-se verificar, pelo número de discordância, que as empresas ainda não delegam poderes para as profissionais de secretariado.

Conforme citado anteriormente por Natalense (1998), a tendência do mercado para os novos papéis secretariais são essencialmente a multiplicidade de tarefas, a liderança e tomada de decisão na organização, o trabalho em equipe com espírito cooperativo para o melhor rendimento do trabalho e o profissional que possuem diferenciais.

Verifica-se, por meio dos resultados da pesquisa, que é importante as empresas reverem o fator da tomada de decisões e permitirem que os secretários tenham poder de decisão diante do seu trabalho. Será importante para o aumento da satisfação e da motivação do profissional, pois ele se sentirá útil e capaz em ajudar a organização com seu trabalho e seus conhecimentos.

Um fator importante para avaliar o reconhecimento do profissional é a sua valorização dentro da organização, pois através destas variáveis pode-se entender melhor como está a motivação dos secretários com relação à empresa, que pode proporcionar treinamentos, cursos e reconhecimento diante do seu trabalho.

O Gráfico 5 dispõe as respostas relacionadas quanto a esses fatores.

Gráfico 5 - Reconhecimento, valorização e recompensa.

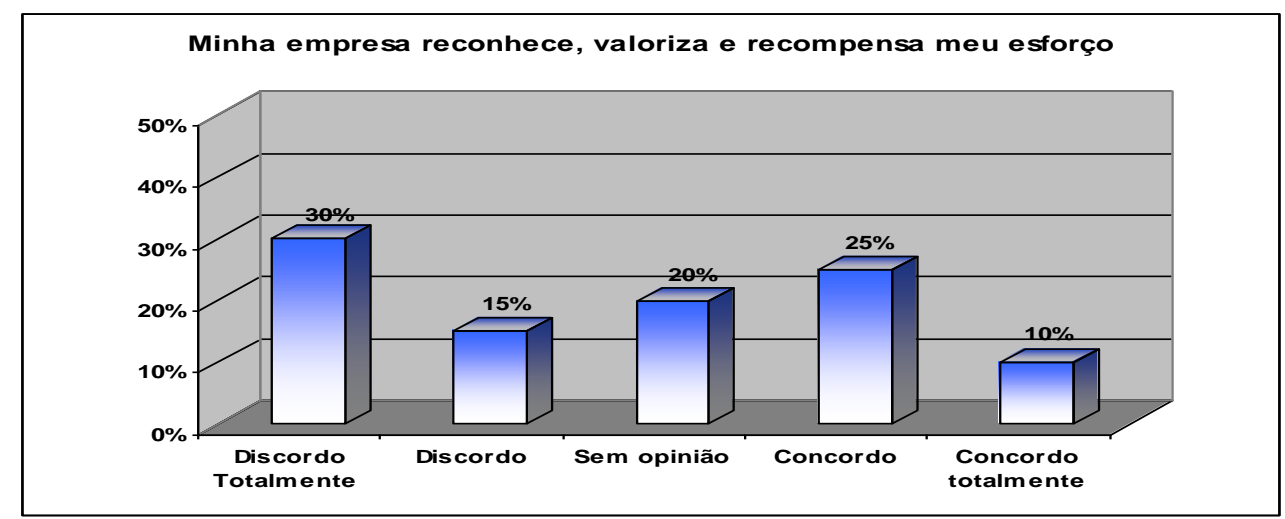

Fonte: Elaborado pelo autor com base em dados coletados.

Revista de Gestão e Secretariado, São Paulo, v. 2, n. 1, p.32-55, jan./jun. 2011. 
Verifica-se que o fator de reconhecimento e valorização teve um índice de discordância, o que não havia ocorrido até o momento, em que 30\% discordaram totalmente que são reconhecidos e valorizados dentro da organização. Um fator preocupante para as organizações e para a motivação das profissionais.

Conforme citado por Newstrom (1989), a integração do homem ao contexto de trabalho, abrangendo a autorealização e o comprometimento diante dela, se dá devido à necessidade de que o homem possa, independente do trabalho que realiza, desenvolver uma concepção abrangente de si mesmo, visando ampliar seu espaço de participação, aliado ao reconhecimento e recompensas. $O$ indivíduo volta a si próprio resgatando sua auto-estima, bem como sentimentos frente a vida.

Newstrom (1989) ressalta ainda que a falta de reconhecimento e valorização estão diretamente ligados a motivação, pois o profissional deve sentir-se reconhecido na organização onde trabalha. Diante dos dados obtidos, é importante que as empresas revejam o fator reconhecimento e valorização, pois todo profissional busca uma melhor forma de trabalho, um ambiente onde ele se sinta a vontade, entusiasmado, onde ele visualize que o seu esforço está sendo valorizado pela chefia e pela organização como um todo. Com isso sua motivação aumentará e ele se tornará um profissional ainda mais dedicado ao alcance das metas.

As organizações devem rever seus processos de recursos humanos, visando melhorar o conceito que esses profissionais têm diante da valorização da empresa para com ele. Melhorias nos processos de gestão de pessoas, como treinamentos, participação nos lucros, feedbacks, participação nos resultados da organização e avaliações periódicas são algumas formas de melhorar a integração entre o colaborador e sua chefia, bem como aumentar a motivação do funcionário para que ele se sinta melhor para trabalhar e reverter melhores resultados á organização.

Diante deste contexto, o questionamento quanto ao que gera insatisfação no trabalho do secretário torna-se importante, pois se pode identificar quais os pontos a serem melhorados. O resultado pode ser visto no gráfico 6 .

Gráfico 6 - O que mais gera insatisfação no trabalho.

Revista de Gestão e Secretariado, São Paulo, v. 2, n. 1, p.32-55, jan./jun. 2011. 


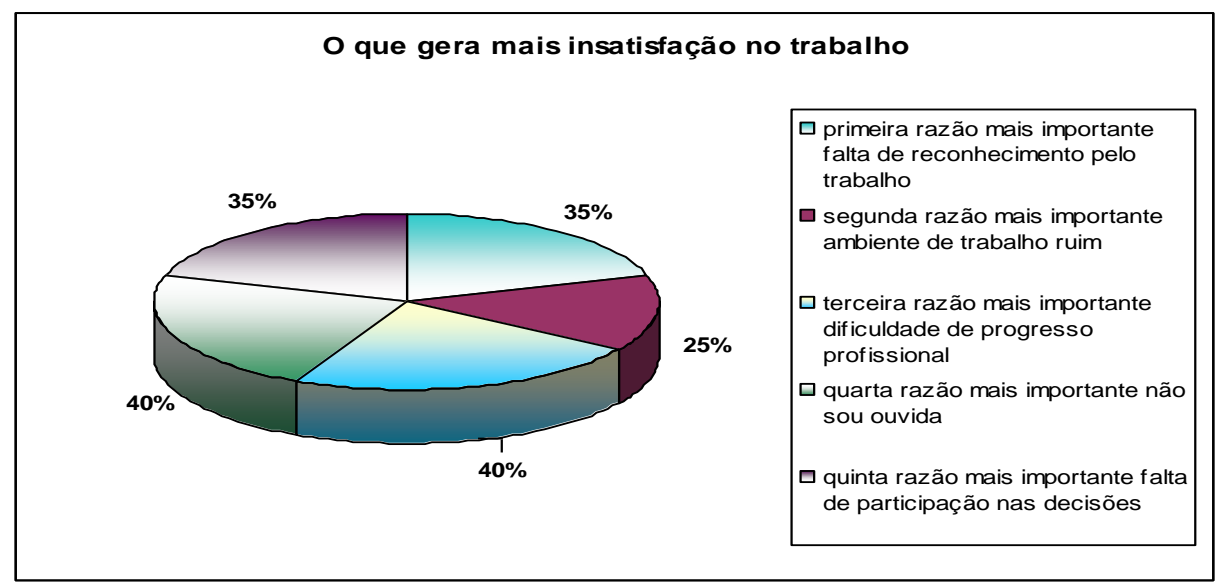

Fonte: Elaborado pelo autor com base em dados coletados.

Dos entrevistados, 35\% consideraram a primeira razão mais importante para a insatisfação no trabalho a falta de reconhecimento diante do trabalho que realizam; $25 \%$ descreveram o ambiente de trabalho ruim como sendo a segunda razão mais importante pela insatisfação. A terceira razão foi destacada como sendo a falta de progresso profissional com $40 \%$. A quarta razão foi a falta de atenção por não ser ouvida, sendo destacada por $40 \%$ das entrevistadas e a quinta razão mais importante pela insatisfação no trabalho foi a falta de participação nas decisões, totalizando 35\% das entrevistadas.

A falta de reconhecimento pelo trabalho realizado foi considerado o ponto principal para a insatisfação no trabalho. Diante disso é importante que as organizações atentem para este fato, pois, conforme Knaane (1999) o trabalho possibilita ao indivíduo exercer sua potencialidade criativa, desde que as condições ambientais e profissionais sejam facilitadoras, levando-o à plena realização. A realização do trabalho será satisfatória se houver um reconhecimento quanto ao trabalho que é realizado pelo funcionário.

Outro fator importante diante dos resultados obtidos são as demais opções selecionadas, em que a dificuldade de progresso profissional, a falta de ser ouvida e a impossibilidade de participar do andamento dos processos da empresa dando sua opinião, foram as mais citadas. Com isso é importante que a profissional se torne parte integrante da organização, buscando conhecimentos, ideias aumentando assim sua chance de crescimento profissional.

Revista de Gestão e Secretariado, São Paulo, v. 2, n. 1, p.32-55, jan./jun. 2011. 


\section{CONSIDERAÇÕES FINAIS}

Os resultados da pesquisa levaram à visão de que o Secretário Executivo exerce sua função de maneira integrada aos demais colaboradores da organização.

No caso deste estudo, quanto mais motivado o secretário estiver, mais ele produzirá e melhorará sua forma de trabalho. O momento atual é de transformações no trabalho e também o surgimento de novos paradigmas. Ao mesmo tempo em que motivar os funcionários de uma maneira particular, acompanhando e valorizando suas conquistas, é uma ótima forma de motivar a equipe, necessidades básicas de sobrevivência como alimentação e saúde devem fazer parte de uma política motivacional, exigindo uma diversificação cada vez maior dos benefícios.

Estímulos como integração social, reconhecimento, treinamento que propicie o aprimoramento técnico, aquisição de novos desafios, possibilidade de criar novos métodos de trabalho, serviços e produtos, além do bom relacionamento com os colegas de trabalho e superiores constituem fatores mais ou tão importantes quanto benefícios que engrossam os salários.

Ainda de acordo com a pesquisa, organizações deste século devem manter um ambiente dinâmico que permita ao seu colaborador interagir, aprender, questionar e crescer conscientemente. As empresas têm suas diferenças, como cultura, modernização, centralização e assim por diante, mas as que sobreviverão são aquelas que conseguirem manter o espírito de equipe, a parceria e a complementaridade nos trabalhos de seus colaboradores, onde nenhum profissional é mais importante do que o outro, pois basta uma pessoa desmotivada para que o resultado final saia diferente.

É importante que as empresas atentem para o bem-estar dos funcionários, pois conforme dados pesquisados, eles não estão satisfeitos pela forma com que a organizações lidam como o bem-estar dentro das organizações. As empresas devem atentar também para a melhoria do feedback, o qual auxilia a gerência na identificação de possíveis problemas ou descontentamentos dos funcionários.

Revista de Gestão e Secretariado, São Paulo, v. 2, n. 1, p.32-55, jan./jun. 2011. 
A ênfase ao comportamento humano nas organizações é um desafio que hoje se apresenta como um das mais valiosas possibilidades e perspectivas para a implantação de programas de qualidade. A satisfação no trabalho é um fator crítico dentro das organizações e necessita ser compreendida, acompanhada e trabalhada de forma a evitar os problemas potencias da insatisfação que podem vir a prejudicar a vida das organizações.

Perceber e buscar formas de melhoria dentro das organizações torna-se essencial para o crescimento do profissional e também da organização, pois os dois devem buscar resultados de uma maneira conjunta. Ampliar o conhecimento sobre o comportamento organizacional fará com que as organizações inovem, cresçam e se desenvolvam de uma forma mais produtiva e competitiva no mercado em que atuam.

\section{REFERÊNCIAS}

CARVALHO, A.P.\&; GRISSON, Diller. Manual do Secretariado Executivo. 3.ed. São Paulo: D'livros, 2000.

DAVIS, K.\&; NEWSTROM, J.W. Comportamento humano no trabalho. São Paulo: Pioneira, 1989.

GIL, A.C. Projetos de pesquisa. 3.ed. São Paulo: Atlas, 2009.

KNAANE, R. Comportamento humano nas organizações: $O$ homem rumo ao século XXI. 2. ed. São Paulo: Atlas, 1999.

NUTTIN, J. Teoria da motivação humana. São Paulo: Loyola, 1983.

RIBEIRO, M.W.M. Profissão Secretária. Porto Alegre: Tchê, 1988.

ROBBINS, S.P. Fundamentos do comportamento organizacional. 7.ed. São Paulo: Prentice Hall, 2004.

Revista de Gestão e Secretariado, São Paulo, v. 2, n. 1, p.32-55, jan./jun. 2011. 
ROESCH, S.A. Projetos de estágio e de pesquisa em Administração. São Paulo: Atlas, 2005.

WAGNER, J.A.\&; HOLLENBECK, J.R. Comportamento organizacional. Criando vantagem competitiva. São Paulo: Saraiva, 1999.

XAVIER, E.P. Comportamento organizacional. Porto Alegre: Bureau, 1973. 